CLINICAL STUDY

\title{
Cholecalciferol loading dose guideline for vitamin D-deficient adults
}

\author{
Lenneke van Groningen ${ }^{1}$, Susanne Opdenoordt ${ }^{1}$, Adriaan van Sorge ${ }^{2}$, Darryl Telting ${ }^{3}$, Astrid Giesen ${ }^{2}$ \\ and Hans de Boer ${ }^{1}$ \\ ${ }^{1}$ Department of Internal Medicine, Ziekenhuis Rijnstate, ${ }^{2}$ Department of Clinical Pharmacology and ${ }^{3}$ Department of Clinical Chemistry, Rijnstate Hospital \\ Arnhem, Wagnerlaan 55, 6800 TA Arnhem, The Netherlands
}

(Correspondence should be addressed to H de Boer; Email: hdeboer@alysis.nl)

\begin{abstract}
Introduction: Severe vitamin D deficiency is very common. Evidence-based guidelines for rapid correction with high-dose oral cholecalciferol are not yet available.

Objective: To develop a practical cholecalciferol loading dose regimen.

Materials and methods: A total of 208 vitamin D-deficient subjects (serum 25-hydroxyvitamin $\mathrm{D}_{3}$ $\left(25-\mathrm{OHD}_{3}\right)$ level $\left.<50 \mathrm{nmol} / \mathrm{l}\right)$, aged $18-88$ years, were treated with solubilized cholecalciferol, $50000 \mathrm{IU} / \mathrm{ml}$. They received either $25000 \mathrm{IU}$ every fortnight for 8 weeks (total dose $100000 \mathrm{IU}$ ), 25000 IU every week for 6 weeks (total dose 150000 IU), or 25000 IU every week for 8 weeks (total dose $200000 \mathrm{IU})$. Blood samples were collected at baseline and 10 days after the final dose of cholecalciferol.

Results: Most patients were severely vitamin D deficient: $76 \%$ had a serum $25-\mathrm{OHD}_{3}$ level $<30 \mathrm{nmol} / \mathrm{l}$ at baseline. Cholecalciferol in a cumulative dose of 100 000, 150 000, and $200000 \mathrm{IU}$ increased mean serum $25-\mathrm{OHD}_{3}$ level by $29 \mathrm{nmol} / \mathrm{l}$ (95\% confidence interval (CI): $\left.23-35 \mathrm{nmol} / \mathrm{l}\right), 43 \mathrm{nmol} / \mathrm{l}$ (95\% CI: $36-50 \mathrm{nmol} / \mathrm{l})$, and $69 \mathrm{nmol} / \mathrm{l}(95 \% \mathrm{CI}: 64-75 \mathrm{nmol} / \mathrm{l})$ respectively. The change in $25-\mathrm{OHD}_{3}$ $\left(\Delta 25-\mathrm{OHD}_{3}\right)$ was related to the dose per kilogram body weight $\left(R^{2}=0.38, P<0.0001\right)$, and is described by the equation: $\Delta 25-\mathrm{OHD}_{3}=0.025 \times$ (dose per $\mathrm{kg}$ body weight).

Conclusion: The cholecalciferol loading dose required to reach the serum $25-\mathrm{OHD}_{3}$ target level of $75 \mathrm{nmol} / \mathrm{l}$ can be calculated as follows: dose $(\mathrm{IU})=40 \times\left(75-\right.$ serum $\left.25-\mathrm{OHD}_{3}\right) \times$ body weight.
\end{abstract}

European Journal of Endocrinology 162 805-811

\section{Introduction}

Vitamin D status is related to sunlight exposure and therefore depends on latitude (1). As a result, vitamin $\mathrm{D}$ deficiency, defined as a serum 25-hydroxyvitamin $\mathrm{D}_{3}$ $\left(25-\mathrm{OHD}_{3}\right)$ level $<50 \mathrm{nmol} / \mathrm{l}$, is very common in Northern Europe. In Germany, for example, $57 \%$ of the 18-79-year-old residents are vitamin D deficient, and this is mainly explained by the lack of sufficient sunlight exposure and low dietary vitamin D (2).

Vitamin D deficiency is well known for its musculoskeletal complications in children and adults $(1,3,4)$. However, vitamin D receptors are also present on a large variety of extraskeletal cell types, including cardiomyocytes, vascular endothelial cells, neurons, immune cells, and pancreatic $\beta$-cells. A rapidly growing body of evidence indicates that vitamin $\mathrm{D}$ deficiency may play a role in the development of common cancers, autoimmune diseases, infectious diseases, and cardiovascular diseases $(1,3,5)$. Consequently, improvements in the detection and treatment of vitamin $\mathrm{D}$ deficiency may have a major health impact.
There is an emerging consensus that serum $25-\mathrm{OHD}_{3}$ levels of about $75 \mathrm{nmol} / \mathrm{l}$ are optimal for bone health and extraskeletal effects $(6,7)$. However, there is no consensus on how to achieve this target rapidly. In the USA, ergocalciferol (vitamin $\mathrm{D}_{2}$ ) is recommended at a dose of $50000 \mathrm{IU} /$ week for 8 weeks, irrespective of the degree of vitamin D deficiency or body weight (1). In Europe, cholecalciferol (vitamin $\mathrm{D}_{3}$ ) is mainly used to treat vitamin D deficiency. Usually, this is done with daily supplementation using tablets.

In 2006, the commercially available cholecalciferol tablets (Devaron $400 \mathrm{IU}$ ) were suddenly withdrawn from the market in The Netherlands. This forced us to look for alternatives to maintain patient care. We were fortunate to discover a formulation for solubilized cholecalciferol (50 $000 \mathrm{IU} / \mathrm{ml}$ ), which was developed by the Dutch Pharmacists Association (Formularium der Nederlandse Apothekers, FNA) 20 years ago, and which included a guideline for quality control. This formulation is not patented, it is cheap to prepare, and can be used everywhere. Nevertheless, it was hardly prescribed, possibly because of unawareness of its 
existence, or due to the lack of evidence-based dosing guidelines. We therefore decided to design a study with the aim to develop a practical cholecalciferol loading dose regimen that would enable rapid correction of vitamin $\mathrm{D}$ deficiency in a heterogeneous population such as that encountered in an outpatient clinic of internal medicine. A cumulative dose of $400000 \mathrm{IU}$ such as that recommended for ergocalciferol was considered to be too high for cholecalciferol. Two studies had provided evidence that cholecalciferol might be 2-3 times more potent than ergocalciferol $(8,9)$. This indicated that a loading dose for cholecalciferol should be markedly lower than that recommended for ergocalciferol. As the exact proportion of required adjustment was not known, it was decided to perform a dose-escalation study.

\section{Subjects and methods}

\section{Participants}

A total of 208 patients with established vitamin D deficiency (serum $25-\mathrm{OHD}_{3}$ level $<50 \mathrm{nmol} / \mathrm{l}$ ) were included. All patients were visitors of the internal medicine outpatient clinic. They had been tested for vitamin $\mathrm{D}$ deficiency because of unexplained fatigue, muscle weakness, myalgia, or unexplained hypophosphatemia. Patients with unstable thyroid disorders, hypoparathyroidism and primary hyperparathyroidism, evidence of malabsorption, and renal insufficiency (glomerular filtration rate $<60 \mathrm{ml} / \mathrm{min}$ ) and those who used medication interfering with vitamin D metabolism were excluded. All patients gave their informed consent.

\section{Study design}

The solubilized cholecalciferol developed by the Dutch Pharmacists Association (Cholecalciferol ${ }^{\mathrm{FNA}}$ $50000 \mathrm{IU} / \mathrm{ml}$ ) is a watery mixture made of cholecalciferol concentrate in oil, citric acid monohydrate, star anise oil, potassium sorbates, polysorbatum 80 (polyoxyethylene sorbitan mono-oleate), sugar syrup, and purified water. The full description of this formulation can be obtained by e-mail, contact: agiesen@alysis.nl. Cholecalciferol is a fat-soluble vitamin that is solubilized by polysorbatum 80 , an interface-active substance that causes micelle formation. After oral administration, the solubilisate changes into a very fine emulsion with better bioavailability than oily formulations $(10,11)$.

As dose guidelines were not available, we had to design a pragmatic dose-escalation study that would be safe to conduct as part of regular patient care. To minimize the risk of over supplementation, the first group of patients (group A, $n=30$ ) was treated with a low dose: 25000 IU every fortnight for 8 weeks, i.e. a total dose of $100000 \mathrm{IU}$ in 2 months. When the laboratory results had confirmed that this dose did not cause hypercalcemia and that the $25-\mathrm{OHD}_{3}$ level had increased by $69 \mathrm{nmol} / \mathrm{l}$ or less, it was decided to increase the loading dose in the next group of patients. They received $25000 \mathrm{IU} /$ week for 6 weeks, i.e. a total of $150000 \mathrm{IU}$ in 2 months (group B, $n=68$ ). Again, hypercalcemia or potentially toxic vitamin D levels were not observed. With this regimen, the four biggest increases in $25-\mathrm{OHD}_{3}$ were $160,130,108$, and $100 \mathrm{nmol} / \mathrm{l}$ respectively, and the other responses were $<100 \mathrm{nmol} / \mathrm{l}$. Complete suppression of serum parathyroid hormone (PTH) had not occurred with this dose, and therefore, it was considered safe to treat the third group of subjects with $25000 \mathrm{IU} /$ week for 8 weeks, i.e. a total dose of 200000 IU in 2 months (Group C, $n=110$ ).

For the analysis of serum $25-\mathrm{OHD}_{3}$, creatinine, calcium, phosphate, albumin, and PTH, blood samples were collected at baseline and 10 days after the final dose of cholecalciferol. This interval was chosen because it was shown by previous studies that about 10 days are required to convert $90-100 \%$ of the absorbed cholecalciferol into $25-\mathrm{OHD}_{3}$ (9). The blood samples were collected throughout the year, between January 2007 and March 2009.

Serum $25-\mathrm{OHD}_{3}$ concentrations were measured by RIA (DiaSorin, Stillwater, MN, USA). The detection limit of this assay is $10 \mathrm{nmol} / \mathrm{l}$, and the intra- and interassay coefficients of variation are 8.1 and $10.2 \%$ respectively. Serum intact PTH was measured by chemiluminescent enzyme-labeled immunometric assay (Immulite 2500, Siemens, Los Angeles, CA, USA).

\section{Statistical analysis}

Results are expressed as mean values \pm s.D. Data that did not follow a normal distribution were log-transformed. Responses to treatment within groups were analyzed by paired, two-sided $t$-tests. Between-group differences were tested by ANOVA and unpaired $t$-tests. To enable calculation procedures, $25-\mathrm{OHD}_{3}$ levels below the assay's detection limit were given a value of $5 \mathrm{nmol} / \mathrm{l}$. Multivariate regression analysis was used to identify the variables that might predict the cholecalciferol loading dose. Variables included for this analysis were season, sex, age, height, body weight, body mass index (BMI), cholecalciferol dose in IU and in IU/kg body weight, and baseline serum $25-\mathrm{OHD}_{3}$. To obtain a simple model that would be easy to use in daily practice, only those variables explaining more than $5 \%$ of the total variance were considered to be clinically relevant, and variables explaining $<5 \%$ of the variance were removed. A $P$ value $<0.05$ was considered to be statistically significant.

\section{Results}

The baseline characteristics of the patients enrolled in the study are shown in Table 1 and Fig. 1. Sixty-two patients had a diagnosis of osteoporosis, and the remaining subjects had a wide array of diagnoses 
Table 1 Baseline characteristics of the study population. Results in mean values \pm s.D.

\begin{tabular}{ll}
\hline & Mean \pm s.D. \\
\hline Age (years) & $55.2 \pm 17.2$ \\
Male/female $(n)$ & $66 / 142$ \\
Height $(\mathrm{cm})$ & $168 \pm 13.7$ \\
Weight $(\mathrm{kg})$ & $80.5 \pm 27.1$ \\
Body mass index $\left(\mathrm{kg} / \mathrm{m}^{2}\right)$ & $28.1 \pm 7.7$ \\
Serum creatinine $(\mu \mathrm{mol} / \mathrm{l})$ & $70.7 \pm 28.3$ \\
Serum total calcium $(\mathrm{mmol} / \mathrm{l})$ & $2.32 \pm 0.09$ \\
Serum phosphate $(\mathrm{mmol} / \mathrm{l})$ & $1.01 \pm 0.19$ \\
Serum albumin $(\mathrm{g} / \mathrm{l})$ & $39.0 \pm 3.2$ \\
Serum 25-OHD & $20.5 \pm 8.7$ \\
Serum $\mathrm{PTH}(\mathrm{pmol} / / \mathrm{l})$ & $5.4 \pm 4.6$ \\
Mean dose $/ \mathrm{kg}(\mathrm{IU} / \mathrm{kg})$ & $2350 \pm 785$ \\
\hline
\end{tabular}

commonly seen in a general internal medicine practice of a teaching hospital. The female:male ratio was $2: 1$. All variables that might affect the magnitude of the loading dose, such as age, body weight, serum $25-\mathrm{OHD}_{3}$, and the month of sampling covered a wide range (Fig. 1). A substantial number of patients were obese: $33 \%$ had a BMI $>30 \mathrm{~kg} / \mathrm{m}^{2}$, and $5 \%$ were morbidly obese (BMI $>40 \mathrm{~kg} / \mathrm{m}^{2}$ ).

The laboratory results at baseline and 10 days after the final dose of cholecalciferol are summarized in Table 2. The majority of patients were severely vitamin $\mathrm{D}$ deficient. Baseline serum $25-\mathrm{OHD}_{3}$ level was $<10 \mathrm{nmol} / \mathrm{l}$ in $12 \%$ of the patients, and $76 \%$ had levels $<30 \mathrm{nmol} / \mathrm{l}$. Cholecalciferol treatment increased the mean $25-\mathrm{OHD}_{3}$ level from $20.5 \pm 7.8$ to 74.8 $\pm 30.2 \mathrm{nmol} / \mathrm{l}(P<0.0001)$. In total, $76 \%$ of the patients achieved a serum $25-\mathrm{OHD}_{3}$ level $>50 \mathrm{nmol} / \mathrm{l}$, and $48 \%$ of patients achieved a serum $25-\mathrm{OHD}_{3}$ level $>75 \mathrm{nmol} / \mathrm{l}$. Hypercalcemia, defined as a serum calcium level $>2.55 \mathrm{nmol} / \mathrm{l}$, was not observed. The mean responses within the groups treated with 100000 , 150000 , or $200000 \mathrm{IU}$ are shown in Table 2. The individual changes in $25-\mathrm{OHD}_{3}$ levels within each group are illustrated in Fig. 2. Baseline $25-\mathrm{OHD}_{3}$ levels were similar in the three groups: $19.0 \pm 7.4,20.4 \pm 9.7$, and $20.7 \pm 8.4 \mathrm{nmol} / \mathrm{l}$ respectively. The mean $25-\mathrm{OHD}_{3}$ increased by $29 \mathrm{nmol} / \mathrm{l}$ in group A $(95 \%$ confidence interval (CI): $23-35 \mathrm{nmol} / \mathrm{l}, P<0.0001)$, by $43 \mathrm{nmol} / \mathrm{l}$ in group B (95\% CI: $36-50 \mathrm{nmol} / \mathrm{l}, \mathrm{P}<0.0001)$, and by $69 \mathrm{nmol} / \mathrm{l}$ in group C $(95 \%$ CI: $64-75 \mathrm{nmol} / \mathrm{l}$, $P<0.0001)$. The mean rise in serum $25-\mathrm{OHD}_{3}$ in group B was greater than that in group A $(P<0.05)$, and the rise in group $\mathrm{C}$ was greater than that in group $\mathrm{B}$ $(P<0.0001)$. The highest post-treatment $25-\mathrm{OHD}_{3}$ levels were observed in the subjects receiving $200000 \mathrm{IU}$ in 2 months. The maximum level was $185 \mathrm{nmol} / \mathrm{l}$ (Fig. 2). A statistically significant decrease in serum PTH was observed only in group C $(5.5 \pm 5.3$ $-4.0 \pm 2.8, \quad P<0.01)$, and complete suppression of serum PTH did not occur (data not shown). Serum creatinine rose from $73.8 \pm 41.1$ to $80.2 \pm 51.2 \mu \mathrm{mol} / \mathrm{l}$ in group $\mathrm{B}(P<0.05)$, and the small increases in groups $A$ and $C$ were statistically not significant.

The range in serum $25-\mathrm{OHD}_{3}$ responses was large. This was in part attributed to the wide dose range that varied from 670 to $4348 \mathrm{IU} / \mathrm{kg}$ body weight. The variability in response to treatment was comparable for the three groups (Fig. 2). Multivariate regression analysis with all factors except the 'dose per kg body weight' showed that the rise in serum $25-\mathrm{OHD}_{3}$ was inversely related to body weight and baseline $25-\mathrm{OHD}_{3}$, and positively correlated with the total dose (variance of the model: $0.43, P<0.0001)$. It was not related to age, sex, body height, BMI, or season in this study population. When the multivariate analysis was repeated, but now with inclusion of the 'dose per $\mathrm{kg}$ body weight', only two statistically significant determinants remained: baseline serum $25-\mathrm{OHD}_{3}$ and the dose per $\mathrm{kg}$ body weight (variance of the model: $0.42, \mathrm{P}<0.0001)$. As the baseline serum $25-\mathrm{OHD}_{3}$ explained only $4 \%$ of the total variance in this model, it was removed, leaving only the 'dose per kg body weight' as a clinically relevant parameter. The increase in $25-\mathrm{OHD}_{3}$, expressed as a function of the dose $/ \mathrm{kg}$ body weight, is shown in Fig. 3. On the left, the complete data set is shown, including the polynomial regression line with its $95 \%$ CI in red $\left(R^{2}=0.40, P<0.0001\right)$. The linear regression line is defined by the equation: $\Delta 25-\mathrm{OHD}_{3}=-1.15+0.024 \times($ dose per $\mathrm{kg}$ body weight), $R^{2}=0.38, P<0.0001$. This line fell well within the $95 \% \mathrm{CI}$ of the polynomial line.
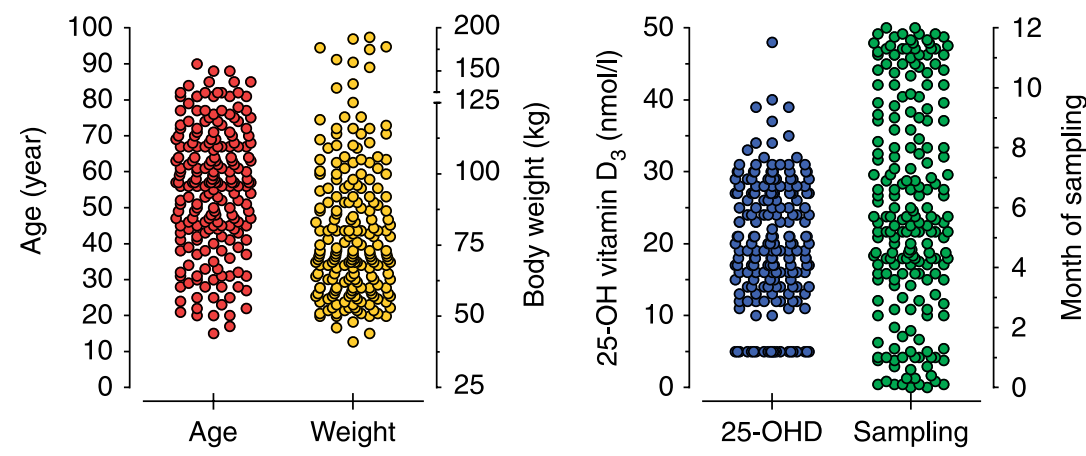

Figure 1 Distribution of age, body weight, baseline serum $25-\mathrm{OHD}_{3}$ levels, and the timing of blood sampling throughout the year. Samples with $25-\mathrm{OHD}_{3}$ levels below the assay's detection limit were given a value of $5 \mathrm{nmol} / \mathrm{l}$. 
Table 2 Comparison of serum calcium, phosphate, parathyroid hormone (PTH), and 25-hydroxyvitamin $\mathrm{D}_{3}\left(25-\mathrm{OHD}_{3}\right)$ levels before and after oral cholecalciferol in patients receiving a cumulative dose of 100000,150000 , or 200000 IU. Results in mean \pm S.D.

\begin{tabular}{|c|c|c|c|c|c|c|}
\hline & \multicolumn{2}{|c|}{$100000 \mathrm{IU}$} & \multicolumn{2}{|c|}{$150000 \mathrm{IU}$} & \multicolumn{2}{|c|}{$200000 \mathrm{IU}$} \\
\hline & Before & After & Before & After & Before & After \\
\hline Creatinine $(\mu \mathrm{mol} / \mathrm{l})$ & $65.7 \pm 14.6$ & $66.2 \pm 13.6$ & $73.8 \pm 41.1$ & $80.2 \pm 51.2^{*}$ & $69.7 \pm 19.2$ & $72.4 \pm 24.0$ \\
\hline Total calcium (mmol/l) & $2.34 \pm 0.11$ & $2.33 \pm 0.18$ & $2.32 \pm 0.09$ & $2.35 \pm 0.12$ & $2.32 \pm 0.09$ & $2.34 \pm 0.10$ \\
\hline Phosphate $(\mathrm{mmol} / \mathrm{l})$ & $1.06 \pm 0.20$ & $1.13 \pm 0.37$ & $1.02 \pm 0.19$ & $1.06 \pm 0.20$ & $1.00 \pm 0.18$ & $0.97 \pm 0.17$ \\
\hline Albumin $(\mathrm{g} / \mathrm{l})$ & $39.0 \pm 3.4$ & $39.7 \pm 3.9$ & $38.8 \pm 3.6$ & $39.0 \pm 3.1$ & $39.0 \pm 3.0$ & $39.4 \pm 2.9$ \\
\hline PTH (pmol/l) & $4.3+1.5$ & $3.5+1.9$ & $5.7+4.1$ & $5.8+7.2$ & $5.5+5.3$ & $4.0+2.8^{\dagger}$ \\
\hline $25-\mathrm{OHD}_{3}(\mathrm{nmol} / \mathrm{l})$ & $19.0 \pm 7.4$ & $48.3 \pm 13.0^{\ddagger}$ & $20.4 \pm 9.7$ & $63.6 \pm 27.5^{\ddagger}$ & $20.7 \pm 8.4$ & $89.7 \pm 26.9^{\ddagger}$ \\
\hline Dose/kg (IU/kg) & & $1495 \pm 378$ & & $2028 \pm 553$ & & $2701 \pm 748$ \\
\hline$\Delta 25-\mathrm{OHD}_{3}(\mathrm{nmol} / \mathrm{l})$ & & $29.3 \pm 15.4$ & & $43.1 \pm 29.1$ & & $69.0 \pm 28.7$ \\
\hline
\end{tabular}

$\Delta 25-\mathrm{OHD}_{3}$, change in $25-\mathrm{OHD}_{3}$ level. For comparison within groups: ${ }^{\star} P<0.05 ;{ }^{\dagger} P<0.01 ;{ }^{\ddagger} P<0.0001$.

To obtain a practical instrument, the linear equation was simplified. The intercept had a $95 \%$ CI of $-11.0-9.4$, and thus did not differ from zero, which allows elimination from the equation. The $95 \%$ CI of slope of the line ranged from 0.020 to 0.028 . This variability allows a minor deviation to a mean slope value of 0.025. Both measures resulted in a more simple equation that would be easy to use in general practice:

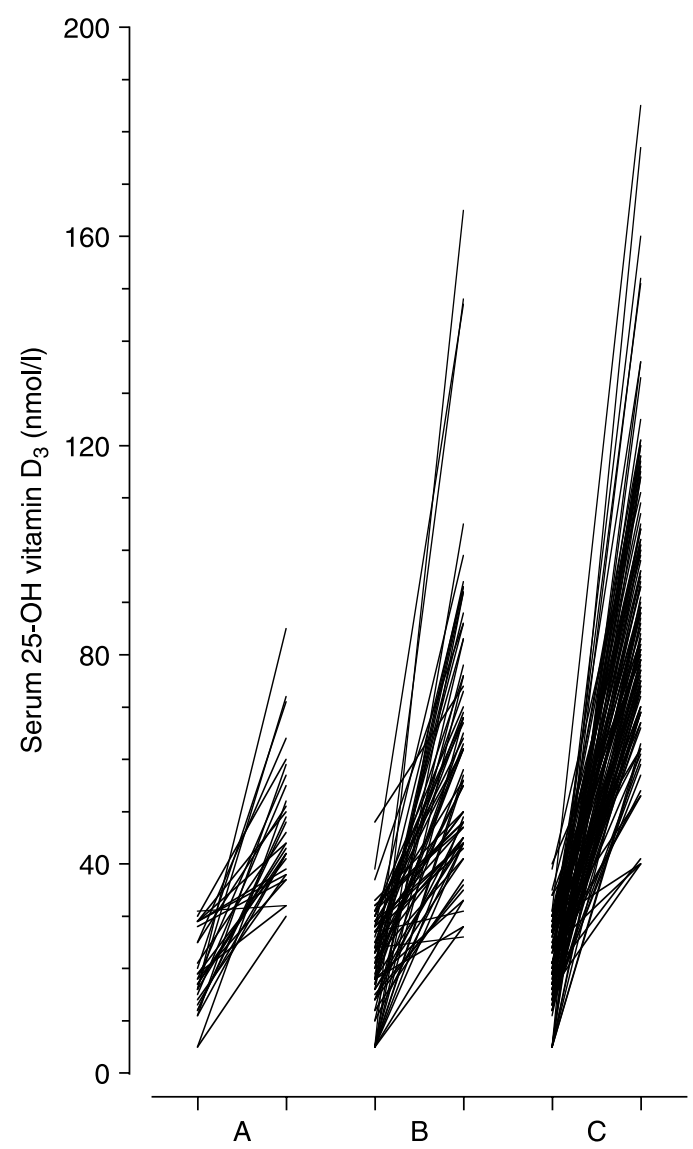

Figure 2 Changes in serum $25-\mathrm{OHD}_{3}$ in response to the oral administration of solubilized cholecalciferol. Group A: $100000 \mathrm{IU}$, group B: $150000 \mathrm{IU}$, and group C: $200000 \mathrm{IU}$.
$\Delta 25-\mathrm{OHD}_{3}=0.025 \times($ dose per $\mathrm{kg}$ body weight $)$. This line also fell within the $95 \%$ CI of the polynomial curve (not shown). The dose required for correction of the serum $25-\mathrm{OHD}_{3}$ level can be derived from Fig. 3 on the right. This figure focuses on the clinically relevant range for vitamin $\mathrm{D}$ correction, i.e. corrections of up to $100 \mathrm{nmol} / \mathrm{l}$. For example, a patient with a $25-\mathrm{OHD}_{3}$ level of $5 \mathrm{nmol} / \mathrm{l}$ will require a rise of $70 \mathrm{nmol} / \mathrm{l}$ to reach the target level of $75 \mathrm{nmol} / \mathrm{l}\left(\Delta 25-\mathrm{OHD}_{3}=75-5=\right.$ $70 \mathrm{nmol} / \mathrm{l})$. To achieve this level, a cholecalciferol dose of $3000 \mathrm{IU} / \mathrm{kg}$ body weight will be required. The loading dose can also be calculated with the equation: loading dose $(\mathrm{IU})=40 \times\left(75-\right.$ serum $\left.250 \mathrm{HD}_{3}(\mathrm{nmol} / \mathrm{l})\right) \times($ body weight $(\mathrm{kg}))$.

It is stressed that this equation should not be used for subjects with body weights $>125 \mathrm{~kg}$. As shown in Fig. 1, only a few patients had body weights larger than $125 \mathrm{~kg}$.

\section{Discussion}

This study has formulated a loading dose guideline for rapid correction of vitamin D deficiency using solubilized cholecalciferol. The calculation of the dose required to normalize serum $25-\mathrm{OHD}_{3}$ is based on the degree of vitamin D deficiency and body weight. It appears to be a safe procedure. In this study, no toxic effects were observed, hypercalcemia did not develop, vitamin D levels never reached the danger range, and complete suppression of PTH levels was not observed. The sampling was well distributed over all seasons, including summer, which further supports the safety of the proposed regimen. The study included young and elderly subjects, lean and obese, with a variety of underlying diagnoses such as those commonly seen in the outpatient clinic of internal medicine in a general teaching hospital. Therefore, the described approach is applicable in a broad array of subjects; however, it is not valid in the case of malabsorption. Once the target level is reached, a maintenance dose will be required to sustain the serum $25-\mathrm{OHD}_{3}$ level around $75 \mathrm{nmol} / \mathrm{l}$. 

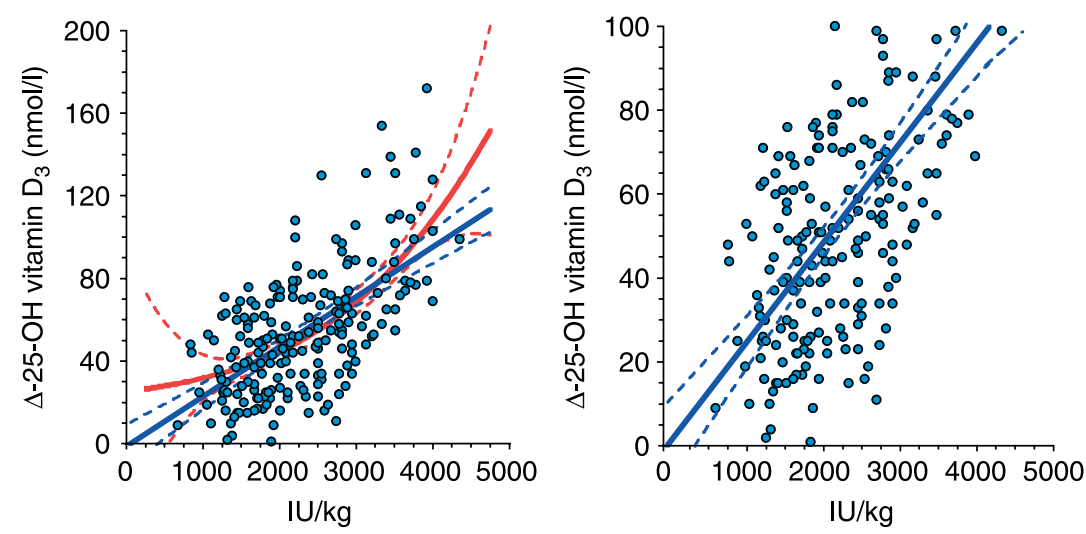

Figure 3 Rise in serum $25-\mathrm{OHD}_{3}$ level as a function of the dose of cholecalciferol, expressed as number of IUs per $\mathrm{kg}$ body weight (left figure). Nomogram to assess the loading dose of cholecalciferol that is necessary to achieve the desired increase in serum $25-\mathrm{OHD}_{3}$ level (right figure).
The present study does not provide data on this. The optimal maintenance dose for solubilized cholecalciferol remains to be determined, and this is currently the subject of further study.

Until recently, vitamin D supplementation studies were mainly limited to elderly people, particularly those who lived in nursing homes where the prevalence of vitamin D deficiency is $75 \%$ or higher. Some studies evaluated the efficacy of high doses at monthly or 3-month intervals, but most studies have used the officially recommended cholecalciferol dose of 600-800 IU/day, or equivalents thereof (12-16). Most studies used predefined fixed doses, irrespective of the degree of vitamin D deficiency and body weight, and assessed the efficacy of the regimen after 4-6 months or longer. These studies were not designed to establish the requirements for a loading dose. A dose of $800 \mathrm{IU} /$ day may help to improve vitamin D status in the long run, but it is not the optimal approach to achieve a rapid correction of severe vitamin D deficiency (16). According to our calculations, a $75-\mathrm{kg}$ patient with a serum $25-\mathrm{OHD}_{3}$ level of $5 \mathrm{nmol} / \mathrm{l}$ will need a total loading dose of $210000 \mathrm{IU}$ to raise the serum level to $75 \mathrm{nmol} / \mathrm{l}$. If, for simplicity, $100 \%$ absorption is assumed, a daily dose of 800 IU will take 3 months to raise the level to $30 \mathrm{nmol} / \mathrm{l}, 5.5 \mathrm{months}$ to raise the level to $50 \mathrm{nmol} / \mathrm{l}$, and almost 9 months to reach the target level of $75 \mathrm{nmol} / \mathrm{l}$.

It is well established that the serum $25-\mathrm{OHD}_{3}$ levels achieved with a fixed dose of oral cholecalciferol are inversely related to body weight or BMI $(17,18)$. This is not unexpected since obese subjects have lower baseline $25-\mathrm{OHD}_{3}$ levels than the non-obese subjects. Also, the rise in serum $25-\mathrm{OHD}_{3}$ will be less in obese subjects because of the larger distribution volume due to the marked increase in body fat. In view of these aspects, we adjusted the loading dose for body weight. Multivariate regression analysis confirmed that the introduction of the factor 'dose per kg body weight' removed the relation between the rise in serum $25-\mathrm{OHD}_{3}$ and body weight. The study population demonstrated a wide range in body weights, and therefore, the equation is considered to be valid for lean, normal, and obese subjects. For the present, however, we advise against its use in morbidly obese subjects, i.e. subjects with a $\mathrm{BMI}>40 \mathrm{~kg} / \mathrm{m}^{2}$. Experience with this subgroup is still too limited to allow firm conclusions.

Discussions on vitamin D requirements and daily allowances are not new. Over the years, the recommended daily dose for adults has gradually increased from 200 to $800 \mathrm{IU}$, and recently, doses of 1000 and even $2000 \mathrm{IU} /$ day or higher have been proposed $(19,20)$. As discussed by Vieth in an excellent review on vitamin D supplementation and safety, many recommendations before 1997 lacked any scientific basis, and the more recent recommendations are often still too low (19). Vitamin D toxicity is often feared for, but usually this fear is unfounded. All published cases of vitamin $D$ toxicity involved intakes of more than 40000 IU/day for a prolonged period of time, with serum 25- $\mathrm{OHD}_{3}$ levels exceeding $>250 \mathrm{nmol} / \mathrm{l}$. To achieve these levels, daily doses of 15000 IU or more for many months are needed. The lowest cumulative dose of cholecalciferol leading to toxic $25-\mathrm{OHD}_{3}$ levels was 3600000 IU given in 3 weeks (19). The loading doses that we have proposed are 10-20 times less, which is another argument to consider them as safe.

Data derived from a dose-escalation study in healthy men with a mean weight of $85 \mathrm{~kg}$ are of interest to compare with those derived from the present method (21). Based on the responses of oral cholecalciferol given in doses of $0,1000,5000$, or $10000 \mathrm{IU} /$ day for a period of 20 weeks, it could be calculated that a rise in cholecalciferol intake of about $57 \mathrm{IU} /$ day is needed to establish a $1 \mathrm{nmol} / \mathrm{l}$ rise in serum $25-\mathrm{OHD}_{3}$. Applied to our population, and given for 8 weeks, a total amount of $57 \times 7 \times 8 \times 50$ or 160000 IU would be required to increase serum $25-\mathrm{OHD}_{3}$ by $50 \mathrm{nmol} / \mathrm{l}$ in an $85-\mathrm{kg}$ subject. This compares well with the $170000 \mathrm{IU}$ that are required according to our calculation model. The advantages of our method are that it is applicable to a broad variety of subjects, and that it allows adjustment 
for body weight. The effect of body weight is considerable: a $50 \mathrm{nmol} / \mathrm{l}$ rise in a $60-\mathrm{kg}$ subject will require a loading dose of $120000 \mathrm{IU}$, whereas a 100-kg subject will require $200000 \mathrm{IU}$.

In the present study, cholecalciferol was given in doses of 25000 IU/week. Higher doses or a higher dose frequency might shorten the treatment period, but it is not exactly known how this will affect the $25-\mathrm{OHD}_{3}$ response. It has been demonstrated that single doses of 50000 or $100000 \mathrm{IU}$ are safe and effective. In nonobese subjects, these doses raised serum $25-\mathrm{OHD}_{3}$ to peak levels of about 15 and $35 \mathrm{nmol} / \mathrm{l}$ within $1-2$ weeks respectively $(9,22)$. The use of these higher doses may alter the vitamin $\mathrm{D}_{3}$ pharmacokinetics to an extent that an adjusted dose calculation might be required. There is evidence that very high doses may saturate hydroxylation reactions, thereby reducing the efficiency to generate $25-\mathrm{OHD}_{3}$ within a given period of time (23).

Another aspect that is relevant to the assessment of loading doses is the ongoing debate concerning the bioequivalence of ergocalciferol and cholecalciferol (8, 9, 23-27). All studies using single boluses or brief treatment periods with relatively high doses of vitamin $\mathrm{D}$ indicate that cholecalciferol is more potent than ergocalciferol in raising serum $25-\mathrm{OHD}_{3}$. This applies to the oral route as well as to the i.m. route (26). Estimates are that cholecalciferol is 2-3 times more potent than ergocalciferol in raising serum $25-\mathrm{OHD}_{3}$. This lower potency has been attributed to a shorter half-life as a result of a lower binding affinity to vitamin D-binding protein (24). In contrast to these observations, ergocalciferol was found to be equally effective as cholecalciferol in maintaining serum $25-\mathrm{OHD}_{3}$ status when treatment was given for a prolonged period of time, e.g. 3 months, and at a much lower dose (25). The magnitude of the dose may be the key to explaining the discrepancy between the studies. As long as this issue is not fully clarified, the recommended dose calculation procedure should only be relied upon to assess the cholecalciferol loading dose.

In conclusion, for rapid correction of vitamin D deficiency, we recommend a cholecalciferol loading dose regimen based on the equation: dose $(\mathrm{IU})=40$ $\times\left(75-\right.$ serum $\left.25-\mathrm{OHD}_{3}\right) \times$ body weight. The equation is based on data derived from subjects weighing $125 \mathrm{~kg}$ or less, and thus, it should not be used in subjects with considerable larger body weights. Furthermore, it is important to note that the calculated loading dose should be given in portions of $25000 \mathrm{IU} /$ week. Higher doses per week or higher dosing frequencies might affect the vitamin $\mathrm{D}_{3}$ pharmacokinetics, and thus require an adjusted dose calculation.

\section{Declaration of interest}

The authors declare that there is no conflict of interest that could be perceived as prejudicing the impartiality of the research reported.

\section{Funding}

This study did not receive any specific grant from any funding agency in the public, commercial, or not-for-profit sector.

\section{References}

1 Holick MF. Vitamin D deficiency. New England Journal of Medicine $2007357266-281$.

2 Hintzpeter B, Mensink GB, Thierfelder W, Müller MJ \& ScheidtNave C. Vitamin D status and health correlates among German adults. European Journal of Clinical Nutrition $2008 \mathbf{6 2}$ 1079-1089.

3 DeLuca HF. Overview of general physiologic features and functions of vitamin D. American Journal of Clinical Nutrition 200480 1689-1696.

4 Dawson-Hughes B. Serum 25-hydroxyvitamin D and functional outcomes in the elderly. American Journal of Clinical Nutrition 2008 88 537-540.

5 Lee JH, O'Keefe JH, Bell D, Hensrud DD \& Holick MF. Vitamin D deficiency. Journal of the American College of Cardiology $2008 \mathbf{5 2}$ 1949-1956.

6 Heaney RP. The vitamin D requirement in health and disease. Journal of Steroid Biochemistry and Molecular Biology 2005 97 13-19.

7 Bischoff-Ferrari HA, Giovannucci E, Willet WC, Dietrich T \& Dawson-Hughes B. Estimation of optimal serum concentrations of 25-hyroxyvitamin D for multiple health outcomes. American Journal of Clinical Nutrition $2006 \mathbf{8 4} 18-28$.

8 Trang HM, Cole DEC, Rubin LA, Pierratos A, Siu S \& Vieth R. Evidence that vitamin $\mathrm{D}_{3}$ increases serum 25-hydroxyvitamin $\mathrm{D}$ more efficiently than does vitamin $\mathrm{D}_{2}$. American Journal of Clinical Nutrition 199868 854-858.

9 Armas LAG, Hollis B \& Heaney RP. Vitamin $\mathrm{D}_{2}$ is much less effective than vitamin $\mathrm{D}_{3}$ in humans. Journal of Clinical Endocrinology and Metabolism 200489 5387-5391.

10 Munzel K. Der Einfluss der Formgebung auf die Wirkung eines Arzneimittels. In Fortschritte der Arzneimittelforschung, vol 10, pp 304-305. Basel, Switzerland: Birkhäuser Verlag, 1966.

11 Kramer B, Gordon SM, Berger HM \& Sobel AE. Aqueous dispersions of vitamins A and D in premature infants. American Journal of Diseases of Children 195182 17-27.

12 Chel V, Wijnhoven HAH, Smit JH, Ooms M \& Lips P. Efficacy of different doses and time intervals of oral vitamin D supplementation with of without calcium in elderly nursing home residents. Osteoporosis International 200719 663-671.

13 Ish-Shalom S, Segal E, Salganik T, Raz B, Bromberg IL \& Vieth R. Comparison of daily, weekly and monthly vitamin $\mathrm{D}_{3}$ in ethanol dosing protocols for two months in elderly hip fracture patients. Journal of Clinical Endocrinology and Metabolism 200893 3430-3435.

14 Bacon CJ, Gamble GD, Horne AM, Scott MA \& Reid IR. High dose oral vitamin $\mathrm{D}_{3}$ supplementation in the elderly. Osteoporosis International 200920 1407-1415.

15 Von Restorff C, Bischoff-Ferrari HA \& Theiler R. High dose oral vitamin $\mathrm{D}_{3}$ supplementation in rheumatology patients with severe vitamin $\mathrm{D}_{3}$ deficiency. Bone 200945 747-749.

16 Hoeck HC, Li B \& Ovist P. Changes in 25-hydroxyvitamin $\mathrm{D}_{3}$ to oral treatment with vitamin $\mathrm{D}_{3}$ in postmenopausal females with osteoporosis. Osteoporosis International 200920 $1329-1335$.

17 Wortsman J, Matsuoka LY, Chen TC, Lu Z \& Holick MF. Decreased bioavailablity of vitamin D in obesity. American Journal of Clinical Nutrition 200072 690-693.

18 Lee P, Greenfield JR, Seibel MJ, Eisman JA \& Center JR. Adequacy of vitamin D replacement in severe deficiency is dependent on body mass index. American Journal of Medicine 2009122 1056-1060. 
19 Vieth R. Vitamin D supplementation, 25-hydroxyvitamin D concentrations, and safety. American Journal of Clinical Nutrition $199969842-856$.

20 Aloia JF, Patel M, DiMaano R, Li M, Talwar SA, Mikhail M, Pollack S \& Yeh JK. Vitamin D intake to attain desired serum 25-hydroxyvitamin D concentration. American Journal of Clinical Nutrition $2008 \mathbf{8 7} 1952-1958$.

21 Heaney RP, Davies KM, Chen TC, Holick MF \& Barger-Lux MJ. Human serum 25-hydroxycholecalciferol response to extended oral dosing with cholecalciferol. American Journal of Clinical Nutrition 200377 204-210.

22 Ilahi M, Armas LAG \& Heaney RP. Pharmacokinetics of a single, large dose of cholecalciferol. American Journal of Clinical Nutrition 200887 688-691.

23 Heaney RP, Armas LAG, Shary JR, Bell NH, Binkley N \& Hollis BW. 25-Hydroxylation of vitamin $\mathrm{D}_{3}$ : relation to circulating vitamin $\mathrm{D}_{3}$ under various input conditions. American Journal of Clinical Nutrition 200887 1738-1742.

24 Houghton LA \& Vieth R. The case against ergocalciferol (vitamin $\mathrm{D}_{2}$ ) as a vitamin supplement. American Journal of Clinical Nutrition 200684 694-697.
25 Holick MF, Biancuzzo RM, Chen TC, Klein EK, Young A, Bibuld D, Reitz R, Salameh W, Ameri A \& Tannenbaum AD. Vitamin $\mathrm{D}_{2}$ is as effective as vitamin $\mathrm{D}_{3}$ in maintaining circulating concentrations of 25-hydroxyvitamin D. Journal of Clinical Endocrinology and Metabolism 200893 677-681.

26 Romagnoli E, Mascia ML, Cipriani C, Fassino V, Mazei F, Erasmo E, Carnevale V, Scillitani A \& Minisola S. Short and long-term variations in serum calciotropic hormones after a single very large dose of ergocalciferol (vitamin $\mathrm{D}_{2}$ ) or cholecalciferol (vitamin $\mathrm{D}_{3}$ ) in the elderly. Journal of Clinical Endocrinology and Metabolism 2008 93 3015-3020.

27 Leventis P \& Kiely PDW. The tolerability and biochemical effects of high-dose bolus vitamin $\mathrm{D}_{2}$ and $\mathrm{D}_{3}$ supplementation in patients with vitamin D insufficiency. Scandinavian Journal of Rheumatology 200938 149-153.

Received 23 December 2009

Accepted 3 February 2010 